\title{
Science and Inclusion
}

\author{
E. Canessa ${ }^{1}$, C. Fonda \\ The Abdus Salam International Centre for Theoretical Physics (ICTP), 34151 Trieste, Italy \\ ORCiD ID: E. Canessa https://orcid.org/0000-0002-9581-9419
}

\begin{abstract}
Background: "Science Dissemination for Scholars with Disabilities" is a noteworthy topic which is still sparse and needs more attention by the scientific community.

Objective: In order to increase interest in the study of science and on access to research without exclusion emphasis needs to be paid towards innovation within a scientific environment. Our hope is to encourage further consideration by the scientific community and present strategies that promote the full inclusion of scholars with disabilities in society.

Methods: This work is the result of research experiences in the field of Science and Inclusion within the activities carried out at the ICTP Scientific Fabrication Laboratory of Trieste, in Italy, over the last eight years. Description of some issues on the use of open source digital technologies available at Scientific FabLabs to support education and scientific know-how for all are assessed, and a collection of interesting novel approaches developed in our SciFabLab are given as examples. The discussion is presented to motivate further research and give technological priorities.

Results: We discuss and show concrete examples on how to make "almost anything" through Scientific FabLabs to disseminate science and remove practical barriers offering people with disabilities more independence and opportunities to study science. Standard theories of Disability in the STEM context are also discussed.

Conclusions: This contribution is relevant from the point of view of the social model in that supportive digital tools developed at Scientific FabLabs can be manufactured with participation, assistance and presence by people with a disability. Through this class of Fablabs, we aim to sustain new generations of scientists without any exclusion.
\end{abstract}

\section{Keywords}

Accessible science education, theory of disability, inclusion, science dissemination. developing countries, fablab

1 Author for correspondence: canessae@ictp.it 


\section{Introduction}

Since the approval of the UN Convention on the Rights of Persons with Disabilities in 2006 (CRPD, [1]), disability and social inclusion have become a fundamental human right issue by the international community together with the special need of medical and financial means. To date, the CRPD has been ratified by 185 UN States [1] setting universal requirements for countries and regional integration organizations to fulfill the rights of persons with disabilities. The right-based and the social inclusion approach is key in addressing disability issues across many development sectors incorporating implicitly science education in the Sustainable Development Goal 4 of the UN 2030 Agenda aiming to "ensure inclusive and equitable quality education opportunities for all" (SDG 4, [2]). Mobilizing resources and implementing innovative and contextappropriate solutions to provide, specially as the COVID-19 pandemic still spread across the continents [3], on-line education leveraging hi- and low-tech approaches [4]. It is estimated that $15 \%$ of the world population of 7.9 billion people have some type of disabilities facing diversity of needs and barriers to inclusion (UNESCO Strategic Mapping [5]).

In this context, the field of science dissemination specific to scholars with disabilities [6] is highly relevant, notwithstanding it has historically been scarcely promoted, because of the lack of awareness on new (low-cost) digital technologies. As a main novelty, people with disabilities can today largely benefit from new open digital technologies found in Scientific FabLabs. This topic comprises ad-hoc technological applications and special activities with particular attention towards innovation within a scientific environment. These should be part of a big effort to establish affordable educational and technological projects directed to people with disabilities, particularly in the developing world. We point out here, that this is particularly relevant in the areas of Physics and Mathematics, where to prepare and training a professional takes several years of studies, exchanges, interactions and reflections. Unfortunately, disabilityrelated research has not been undertaken extensively in these fields. Because of these barriers to education there are only few people with disabilities actively participating in scientific research $[7,8]$. Further participatory research and the training of people with disabilities in participatory research requires in particular development of tailored tools and special planning, as for instance, to monitor participation [8]. Participatory methods in research -specially with respect to issues around disability, requires input from the participants (to better understand their condition) and encouraging multi-dialogues. Scientific FabLabs are open spaces that facilitate, and can approach, such essential interactions.

As reported by Watters et al. [9], people with a disability are $19.9 \%$ less likely to work in Science, Technology, Engineering, and Mathematics (STEM) than those people without disability. This suggests that scholars with disabilities are unmotivated to pursue STEM education and employment (as from the statistics by the U.S. Bureau of Labor Statistics 2020, [10]).

The aim of this paper is to increase interest in the study of science, and on access to research, without exclusion. We encourage further consideration by the scientific community and present strategies that 
promote the full inclusion of scholars with disabilities in society. We also invite this community to reflect more on concrete approaches to support disadvantaged groups on their fundamental right to participate, learn and contribute fully to the progress of science using the new technologies.

We briefly analyze how science education without exclusion can be further supported using the digital technologies found under the umbrella of Scientific Fabrication Laboratories [11,12], and in compliance with the CRPD standards and requirements [1]. We highlight how within activities of SciFabLabs, the implementation of digital open technologies as microcontrollers, Apps for mobile devices, 3D printing and other machinery can be adopted to help creating and disseminating scientific knowhow as part of a common global effort. The present work is the result of research experiences in the field of Science and Inclusion within the activities carried out at the ICTP SciFabLab of Trieste, in Italy over the last eight years [11].

The paper is organized as follows. In Section 2 we present an overview of relevant new digital technologies found in FabLabs, and some recent novel approaches, to deal with the problem of inclusion of people with disabilities in education and in STEM. In Section 3 we comment on the underrepresentation of scholars with disabilities in academia and their exclusion from research positions in general. We also analised the educational STEM perspectives, yet to be defined in an integrative theoretical framework. In Section 4 we discuss on the new digital technologies and assistive devices found in and outside FabLabs for people with disabilities, and highlight our experiences in the subject. We conclude the paper in Section 5, with an outlook on how FabLabs can help to turn ideas into a reality, for the benefit of all.

\section{Overview of new digital technologies for inclusion and novel approaches}

Further efforts to include participatory experiences by, and research done with, people with disabilities will enrich future policies or programs [8]. Extra attempts should be made to create further awareness on the topic of disability research and knowledge of effective approaches through low-cost solutions for/in developing countries. We have selected below some relevant studies which are by no means exhaustive and are not yet finalized.

In the following, we describe some examples of how low-cost 3D printers and other digital fabrication technologies can be applied to create solutions to mitigate common physical disabilities such as vision impairment and deaf (or hard of hearing). Such devices are mainly developed within special Laboratory workplaces, Fablabs and Makerspaces. In particular, we illustrate the development of our prototypes for an automated voice-controlled system to reproduce the sign language and for the reproduction of special mathematical structures. Typical (regular size) 3D maths structures can be printed in few hours, consume little plastic material and are cost effective. However, the 3D printing and recreation of more complex bodies, with high accuracity and large tactile details, can be more difficult, expensive and timeconsuming to develop. For example, the 3D printing of the Comet shown in the Figure below, can take more than 9 hours. A large set of other 3D models and resources as e.g., 3D elevation maps and planetary 
landscapes are available at NASA Fablab: https://nasa3d.arc.nasa.gov/detail/fablab

We also include next other special modern platforms developed for teaching accessible science and to facilitate the learning process. We have chosen all of these particular examples motivated by the fact that they cover different areas of science: ranging from Mathematics, Physics to Biology.

These few examples, under continuous developments and improvements since a few years, give an indication of some up-todate projects and topics taking place which can be useful as a starting point for those getting interested in the subject. Some converging topics, projects and affordable technologies for assisting new scholars with disabilities include among others:

\subsection{SciFabLabs and Makerspaces experiences on disability}

Today, the application of a new idea can be facilitated by its development inside Fabrication Laboratories (FabLabs), available as a community resource offering a set of versatile digital tools for prototyping. Tools includes laser engraving and cutting machines, to build $2 \mathrm{D}$ and $3 \mathrm{D}$ structures, CNC milling machines to make circuit boards and precision parts, low-cost 3D printers and scanners, and electronic components and programming tools for microcontrollers (see Figure 1). These FabLabs aiming to support invention and creativity are now also found inside Universities and Research Centers worldwide [11]. This class of multi-purpose workplaces within academia offers an extra support for STEM education and development. Special personalized applications using FabLabs tools can be developed and reproduced, for instance, to approach students with visual impairment and low-vision. Academic STEM activities of interest are mostly developed around FabLabs inserted in a scientific framework. SciFabLabs open new dimensions to science and education specially in developing countries (see, e.g., [7]), and are strongly rooted locally by catalyzing innovation and entrepreneurship also with the help of its faculty and students.

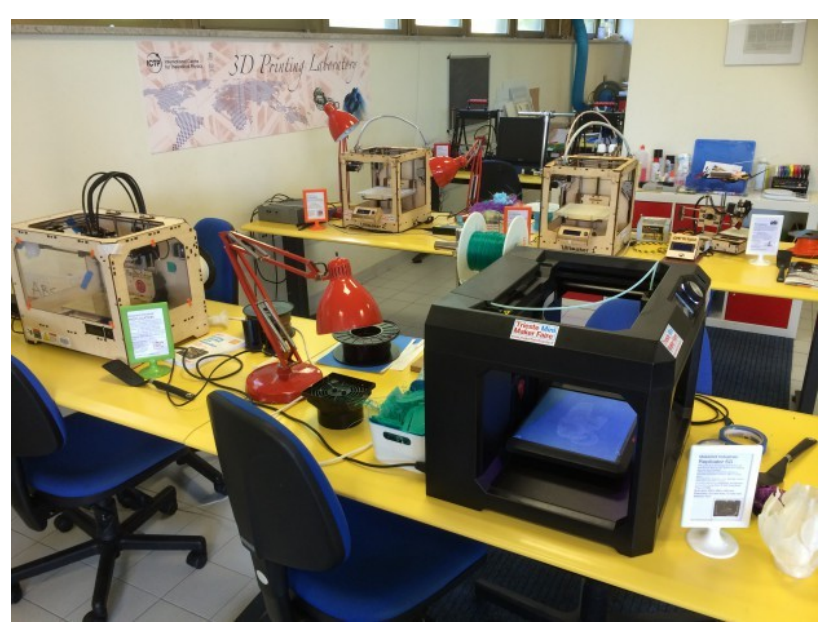

Fig. 1: SciFabLab view. Typical resources include $3 D$ printers (FDM, DLP), 3D scanners, Plastic filament struders, Laser cutting/engraving, CNC milling machine, Plotters, Micro-controllers (Arduino, RasPi, etc).

As pointed out in [13], "digital fabrication spaces" can be found in a variety of public environments, e.g., schools, universities and museums. Fablabs are more likely to be situated within these educational institutions since they serve to promote STEM and Arts knowledge and engage participants in equitable education opportunities (see discussion in [14]). The extent to which they are available across educational environments can be found, e.g., in the published list of Centres for Maker Innovation and Technology (CMIT) developed by the EU Commission [13]. Fablabs within educational institutions 
provide scholars with a facilitated access to complex digital technologies (such as micro electronics and robotics, 3D modelling and printing), and can help to promote knowledge sharing between students, so that they can create, design and prototype their own devices. Education of science students has enriched through new venture creation processes within Fablabs by acquiring new particular skills. Fablabs also provide unique opportunities for students with disabilities (e.g., developing applications as the one in Figure 2). Fablab's role in education is to be effective in fostering today's digital skills combined with hands-on 'making' skills in a collaborative open, educational enviroment.

\subsection{Access to digital fabrication technologies via the EU NEWTON platform}

Remote access to digital fabrication laboratories is allowed within the European Union NEWTON technologies [15]. Further enhanced learning in this project is estimulated via augmented and virtual reality apps, virtual laboratories, richmedia, and delivery of multiple sensorial media. These modern technologies are used in a management platform that facilitates learner-teacher interactions and make learning more attractive to the students, specially university students with special needs and disabilities. This focused research on access to digital fabrication is a new way to promote inclusive, new makercentred educational initiatives of young students in vulnerable social environments, and students with disabilities and learning difficulties in Higher Education. This approach has been validated in the Spanish university system, where only about $5 \%$ of people with disabilities have received university studies.

\subsection{Laboratory workplace for students with visual impairments}

Availability of a science laboratory accessible to students with blindness and low-vision is lacking in science education. These students are usually exposed to formal audio lecturers and are largely denied from full participation in practical laboratory work. Students with visual impairments remain passive learners which depend on the support by lab assistants to complete their hands-on work. However, their access to laboratory devices by themselves -as required in modern science education, are slowly being improved. For example in [9], a new tool for Virtual Lab Assistance is being developed by using voice control capabilities provided by Amazon's Alexa-enabled Echo smart devices and smart speakers and a Raspberry Pi microcontroller. This novel approach to assist general science lab procedures via smartphone or Amazon's device, is very promising to promote the inclusion of more learners to science education work.

\subsection{Voice-controlled sign language systems}

Research into voice-controlled robotic hands that reproduce to some extent the sign language initiated with the pioneer work at the ICTP SciFabLab by Gatti et al. [6].

The goal is to allow individuals with hearing impairment to communicate to thus facilitate their inclusion into society. These class of man-machine interaction projects integrates different open technologies of FabLabs (3D printed manufactured hands using OpenSCAD modeling, Arduino and Raspberry $\mathrm{Pi}$ microcontrollers) or still images sequences displayed on 
smartphones or small video screens (as shown in Figure 2).

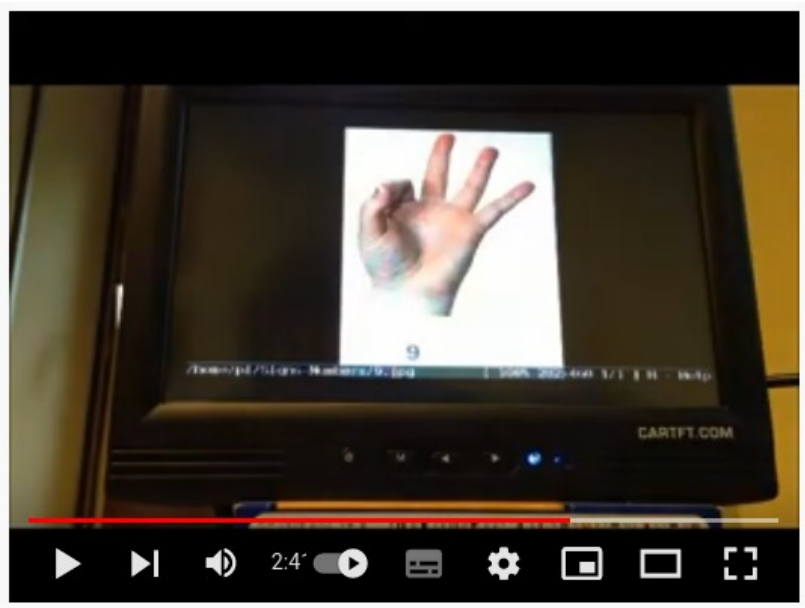

Fig. 2: Voice controlled sign language -demo video at https://www.youtube.com/watch? $v=D R F X C L f 26 w l$

The Arduino controller activates six servo motors following instructions from a Raspberry $\mathrm{Pi}$ mini-computer running the open source speech decoder Julius and some ad-hoc scripts. This automated translator for communication with people who are deaf may help reduce language barriers. More recent prototypes based on digital technologies that also reproduce to some degree a sign language via voicecontrolled robotic hands can be found in Refs. [16,17].

\subsection{Making mathematics tangible at SciFabLabs}

A new dimension for science dissemination is provided with the use of 3D printers within SciFabLabs to produce complex mathematical objects such as the IMAGINARY Open Mathematics Exhibition [7]. The shape of such objects is otherwise difficult to visualize through books or perspective drawings. Not only these can be better visualized, and reproduced in countries with poor scientific infrastructure, but also used as tactile educational objects.

They are directed to persons with disabilities in a more intuitive manner to help improving deeper understanding and put education literally in their as shown in Figure 3.

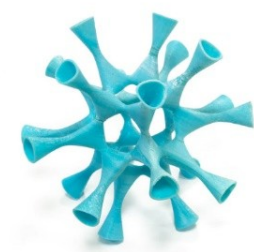

Fig. 3: Examples of 3D printed complex mathematical surfaces.

\subsection{Astronomy and disability}

The terms used in science in general are highly specialized. Astronomy, Astrophysics and other areas of physics science, does not develop on notations and symbols for the students with disabilities. For example, engagement of students who are blind, visually impaired or deaf into Astronomy faces considerable challenges. New planets, stars, galaxies, etc. are discovered every year, and creating signs for these is a difficult task that puts students who are deaf at a disadvantage. Ensuring sign language keeps up with the new discoveries in science and will ensure scholars with hearing impairment to be part of the advancement of science. For example, sign experts are making attempts to gradually develop new universal astronomy signs $[18,19]$. Tactile and 3D printed objects to represent cosmic phenomena allows students' enthusiasm to grow and can be used to give understandable meaning of our Universe. These researches prevent the community of people with disabilities from being excluded from modern science and teaching of several important discoveries. 

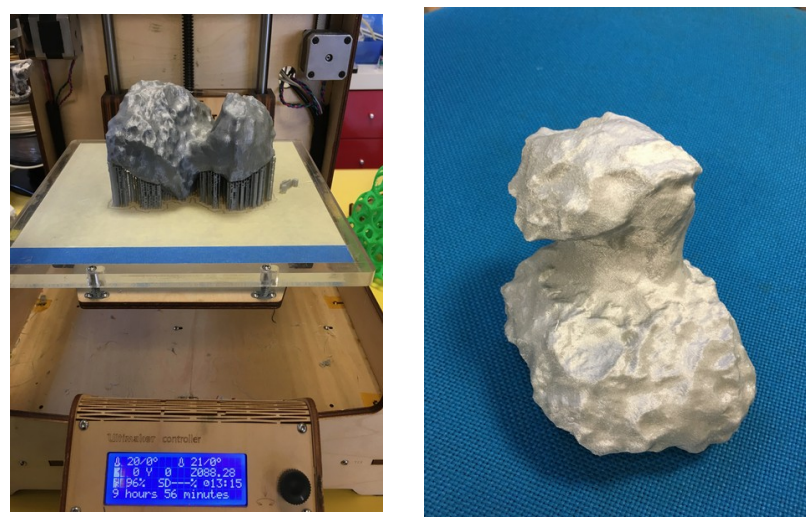

Fig. 4: Tactile 3D model of Comet ChuryumovGerasimenko.

On the other hand, blind or visually impaired audiences cannot participate fully, e.g., in NASA's X-ray discoveries and observations when visual media is the primary sharing mechanism. In order to address equity of accessibility to such findings, the creation of $3 D$ printed data sets to create tactile 3D models are being developed in Ref.[20]. One of such 3D printed example of Comet ChuryumovGerasimenko as imaged by Rosetta spacecraft in 2015, is shown in Figure 4.

\subsection{Scuba Blind International: Learning marine biology}

Scuba Blind International is an unique association aimed mainly at improving the life of blind and visually impaired scholars as well as their social inclusion (Scuba Blind International [21]). This association has conceived, developed and fine-tuned a project for the elaboration of a brand new educational methodology for learning marine biology by teaching scuba diving to persons with blindness and other disabilities. Their method -consolidated with standards, didactic 3D printed aids and published manuals, prioritizes aspects of the observation and knowledge of naturalistic and environmental aspects by the direct immersion in undersea habitats.
Their main achievement is not longer to consider a blind person to be passively transportable underwater, but rather to be an absolute protagonist while diving, with the contribution of a guide companion limited to the sole role of surveillance. This methodology offers an extraordinary educational power from a psychopedagogical point of view. Underwater activities for persons with blindness and motor disabilities without limits, with an adequate training, manages a principle of "conscious autonomy" of the blind and, at the same time, of authentic environmental knowledge.

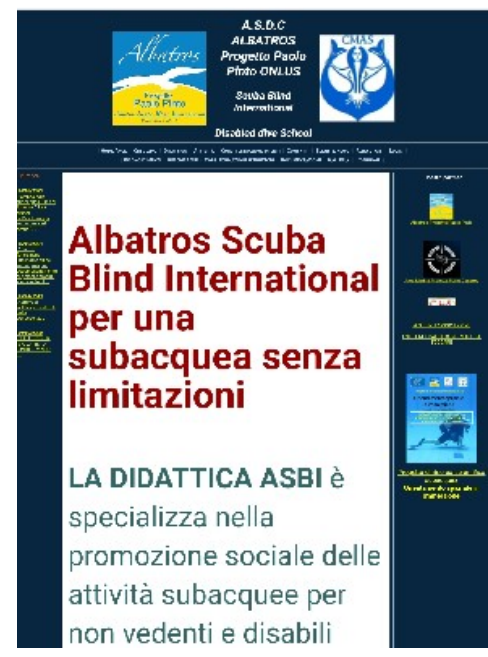

Fig. 5: Scuba Blind School website [21].

We have carefully seleted all of these examples of apllications for assisting scholars with particular attention to show a diverse variety of educational approaches. Full details have been presented whenever possible and associated references to each project has been listed. Such examples reflect the ideas and motivitation behind our paper. Such assistive technologies and approaches of interest for inclusion together (with the adoption of open software) can also be popularized at large-scale through public outreach activities such as Maker Faires and through relevant workshops. 
Promoting rights and facilitating access to science without exclusion through effective participation of persons with disabilities, leads to reduce harmful social practices and wrong perceptions. Stressing the latter ishould be the rationale behind the organization of future focused workshops to support people with disabilities.

\section{Underrepresentation of people with disabilities in academia and disability theory in the STEM-related context}

People with disabilities are excluded from academic and research positions in general. To understand this phenomena, there is an urgent need for research and attention to the lived experiences of disability discrimination (ableism) among faculty and staff in academia and the impact that this has on their mental health, well-being and career development.

For example, the systematic review in [22] highlights ableism among faculty and staff by involving hundred participants across different countries over a two decades period. Faculty and staff people with disabilities not only encounter barriers in their workplaces (e.g., inaccessible physical environments, lack of adaptations to existing facilities and services among others), but not only they find significant under-representation within academia, but sometimes they experience discrimination, unfair treatment and marginalization by their professional peers. Coping mechanisms and strategies to address such ableism in academia are discussed in Ref.[22].

The underrepresentation of people with disabilities amongst academic staff in the field of STEM is indeed significative. As discussed in [23], less than $7 \%$ of Canadian university professors, instructors, teachers or researchers self-identify as having a disability, compared to $20 \%$ in the workingage population. An estimated $<6 \%$ of Australians declare having a disability within academia compared to $18 \%$ of working-age adults. In the UK, only $2 \%$ of staff in universities has a declared health condition compared to $16 \%$ among working-age population. These tiny values not even compare to the small amount of females who are joining academia from professional and graduate schools, which are far from reaching the same ratio as their male counterparts resulting also in an underrepresentation of females in academia. It has been established that women occupy "only" $15 \%$ of full professorship and/or tenured positions in 27 countries of the European Union [24]. There is a huge need of people with disabilities working in academia, who understand better their problems at all levels. Drawing attention to the (perceived) needs and experiences of scholars with disabilities is generally associated to multidisciplinary research within the academic fields of sociology, ethics, humanity, education, psychology, moral/theology and philosophy [25]. Of these, the (bio)medical model of disability has replaced the moral model due to the significant advances in the field of medical science. The shortcomings of the medical model fails to take account of the vital distinction between sickness, rehabilitation and ongoing impairment. On the other hand, in the social (or minority) model of disability, the experience of disability by people with impairments is socially constructed.

Disability as a human rights policy offers in addition a viable framework for the human dignity of people with disabilities. Such theoretical studies can be considered today the dominant models of disability [26]. Disability in education within the social model acknowledges that i) all scholars have special needs instead of being considered as special cases, and ii) all of their talents should be recognized.

In the present context of science and inclusion, disability can be primarily considered social in nature. As a contribution towards developing a disability 
theory, we highlight here the role that new digital technologies have and can play in applications to support scholars with disabilities to guide the formulation of new policies for inclusive STEM education and training in science.

STEM education conforms a large range of advanced knowledge and span across (at least) four different disciplines. Having skills in STEM-related areas offers more workrelated opportunities for all in today's connected world. However, it is a fact that scholars with disabilities perform below their peers without disabilities in math and science [27]. Educational STEM perspectives has yet to be defined in an integrative theoretical framework. It is necessary to explore various ways to implement a general school curriculum among the STEM areas merging the 21st century competencies and technologies to approach the needs of students interested in science and having disabilities.

The use of open digital technologies available at Scientific Fablabs to support education and scientific know-how for all is essential to construct a theoretical framework. It is important to investigate how special materials and tangible educational objects built in FabLabs can be better tailored for students with disabilities. It is also necessary to explore how best we can attract children and young people with disabilities towards scientific research incorporating, for instance, the reality of economic inequalities faced by people with disabilities [28]. Such an alternative approach to inclusion and equality combining STEM education and the establishment of even more Digital Fabrication Laboratories at Schools and Universities, could become of benefit to the whole society and not just to people with disabilities. Overcoming disability with the support of Physicists and Mathematicians plus the use of new digital technologies will be a positive signal for human progress on long-terms.

\section{Discussion}

This work is the result of research experiences in the field of Science and Inclusion. Description of the use of open source digital technologies available at Scientific FabLabs to support education and scientific know-how for all are assessed, and a collection of interesting novel approaches have been given as examples. These approaches are relevant from the point of view of the social model since supportive digital tools developed at Scientific FabLabs can be manufactured with participation, assistance and presence by people with disability.

In particular we wanted to communicate our experiences in science dissemination with the use of 3D printers within SciFabLabs to produce complex mathematical objects such as the IMAGINARY Open Mathematics Exhibition (examples shown in Fig.3), our unique voice-controlled sign language systems to communicate science [6] and the printing of astronomic bodies to teach scholars with disabilities (examples in Fig.4), among many others.

Our analysis on concrete approaches to support disadvantaged groups can be framed against the role of universal design for learning (UDL) via barrier-free inclusive learning environments and the promotion of the right to full and equitable access to education for all [29]. As shown by the concrete examples selected in the manuscript for assisting new scholars, Scientific FabLab environments can help scholars with disablities feel secure, learn 
at their own pace, and offer them equal opportunities to succeed, demonstrate their full potential, and develop their own ideas. One can make then connections with disability, diversity and inclusion within the context of technology and science via the establishment of, and the work carried out at, this class of FabLabs. These Makerspaces embrace an open environment free of access barriers, responds to the diversity of learners, and incorporate their diverse abilities in science and technology. Hence, students can get more motivated to access educational material by making science more tangible.

On the other hand, programs for Science and Inclusion have been organized via workshop activities in recent years, as those held in 2014 and 2017 in Trieste, Italy [30]. Plans are underway to continue with this class of workshops on this relevant and scarcely promoted topic in the future. In a balanced mix, these activities combine technical details, general overviews and sense of the possible. There must also be continuous discussions with experts and scientists experiencing disabilities themselves to ensure how the problems are relevant and appropriate [31,32,33].

Analysis of new ways to establish and guide the creation of modern SciFabLabs and Makerspaces in remote areas designed to be open places devoted to creativity for the benefit of the whole society are also necessary. Few other relevant topics to undertake in the discussions are the path learning and navigation system for the blind using GPS and sensor technologies, video lectures for students that are visually impaired, online learning and people with disability, social networking and thought to speech conversion via brainwaves, further use of mobile devices to promote education for all, interactive lecturing tools to comment lecture Podcasts and to empower learners with disabilities, video games for rehabilitation and education, eye-tracking systems to foster cognitive enhancement, communication and technologies for autism and contextual terms to support students with a physical disability. The establishement of Scientific Fablabs is essential in this process.

People with disabilities should not be overlooked when designing STEM education and public scientific outreach activities. As mentioned, persons with disabilities are observed to be too few in the area of STEM. More open activities as discussed, give a visibility to the possibility of encouraging a person with disability into STEM. In addition, these help to create awareness among the counterparts on the capabilities of persons with disabilities. The present work included details on support systems restricted to the use by students with vision and hearing impairment only with suitable examples in science. In principle scholars with disabilities as motor disabilities, autism spectrum disorders and specific learning disabilities may too benefit from new open digital technologies developed in Scientific FabLabs. A brief review on new technologies and (sometime expensive) assistive devices fabricated outside FabLabs for such students that could be incorporated under digital manufacturing can be found in ("Assistive technologies for people with disabilities"), [34]).

\section{Conclusion}

Our hope here has been to promote another front for research on the subject of science dissemination to everyone and to urge further consideration by the scientific community. Few examples on the state-of- 
the-art topics and discussions have been given (under continuous developments and improvements), requiring the adoption of digital technologies reproducible at SciFabLabs. There are many review articles in the literature discussing the different theoretical models of disability which explain the different approaches and concepts involved. To discuss on each of these approaches is beyond the scope of our paper. Insights on the value of the social model of disability adopted in our paper have been presented -specially for what concern removing barriers to learning and participation on scientific research giving novel opportunities to people with (any type of) disabilities. Our theoretical analysis, motivated by the concrete examples discussed to support disadvantaged groups, largely describes barrier-free inclusive learning environments through Scientific FabLabs having equitable access to science education for all.

We conclude emphasizing that people with disabilities should not be excluded from dissemination and research projects in which they are the focus $[11,35]$. We can all help effectively achieve the proposals as per CRPD [1], through the different abovementioned actions, including Fablabs' activities for delivering tailored technologies for students with disability to sustain new generations of scientists without any exclusion

There are many Fabrication Laboratories and Makerspaces around the world used to transform ideas into tangible objects or to create supportive and assistive devices see $[11,13,14]$ and the recent comprehensive study in [36]. A recent open access compendium (Parts I and II) of assistive technology, accessibility and (e)inclusion published on the occasion of
ICCHP-AAATE 2022 can be found in Ref. [37]. However, there are only a few focused Scientific Fablabs and Makerspaces dedicating efforts and resources to explore the use of open source digital technologies to support special education and scientific know-how for all, with the goal to enlarge the research areas and technological priorities to cover science and inclusion. An example to make some scientific topics inclusive is USA Harvard's Chandra X-ray Center https://chandra.cfa.harvard.edu/tactile/.

Our contribution can be relevant from the point of view of the social model in that supportive digital tools developed at Scientific FabLabs can be manufactured with participation, assistance and presence by people with disability. Social barriers towards science education, research and inclusion for all can be reduced in this way. The aim is to make "almost anything" through FabLabs (Gershenfeld, [38]) to disseminate science and remove barriers offering people with disabilities more independence and opportunities to study science.

\section{Acknowledgements}

The authors would like to thank the members of the ICTP SciFabLab for their collaboration and enthusiasm.

\section{Authors Contributions}

E.C. and C.F. contribuited to the manuscript on equal grounds for conception, preparation and the revision for intellectual content . Supervision was done by E.C.

\section{Ethical Considerations}

This work is exempt from any Institutional Review Board approval. 


\section{Conflict of Interests}

The authors have no conflicts of interest to report.

\section{References}

[1] CRPD 2022 -UN Convention on the Rights of Persons with Disabilities:

https://www.un.org/development/desa/disab ilities/convention-on-the-rights-of-personswith-disabilities/convention-on-the-rights-ofpersons-with-disabilities-2.html (Retrieved Oct 2022).

[2] SDG 42018 -UN Sustainable Development Goal 4: https://www.un.org/sustainabledevelopment leducation/ (Retrieved Oct 2022).

[3] Parida M., and M. Sinha M. Pandemic and disability: Challenges faced and role of technology. Tech. and Disability 2021; 1: 18. doi: 10.3233/TAD-200311

[4] Canessa E., and Tenze L. Ideals and Virtual Realities. iJET 2021; 16: 201-209.

[5] UNESCO Strategic Mapping 2021: UNESCO's work on Disability Inclusion and Rights.

https://www.unesco.org/en/articles/callexpression-interest-strategic-mappingunescos-work-disability-inclusion-and-rights (Retrieved Oct 2022).

[6] Gatti J., Fonda C., Tenze L. et al. VoiceControlled Artificial Handspeak System. Int. J. Artificial Intelligence \& Appl. (IJAIA), 2014; 5: 107-112. doi: 10.5121/ijaia.2014.5108

[7] Fonda C., and Canessa E. Making Ideas at Scientific Fabrication Laboratories. Phys. Education 2016; 51. doi: 10.1088/00319120/51/6/065016

[8] Kuper H., Hameed S., Reichenberger V. et al. Participatory Research in Disability in
Low- and Middle Income Countries: What have we Learnt and what Should we Do?. Scandinavian J. Disability Res. 2021; 23: 328-337. doi: 10.16993/sjdr.814

[9] Watters J., Hill A., Weinrich M. et al. An Artificial Intelligence Tool for Accessible Science Education. J. Sci. Edu. Students with Disabilities 2021; 24: 1-14. doi: 10.14448/jsesd.13.0010

[10] U.S. Bureau of Labor Statistics 2020: Persons with a Disability: Labor Force Characteristics.

https://www.bls.gov/news.release/disabl.nr0 .hhtm (Retrieved JuneOct 2022).

[11] SciFabLab 2022: Scientific Fabrication laboratory website http://scifablab.ictp.it (Retrieved Oct 2022).

[12] FabLabs around the world 2022: http://www.fablabs.io/labs (Retrieved Oct 2022).

[13] Raynaa T., Striukovab L. Fostering skills for the 21st century: The role of Fablabs and makerspaces. Technological Forecasting \& Social Change. 2021; 164: 120391. doi: 10.1016/j.techfore.2020.12039

[14] González-Nieto N.A., Ching-Chiang L.W. et al. FabLabs in vulnerable communities: STEM education opportunities for everyone. Int J Interact Des Manuf (IJIDeM). 2020; 14: 1535-1555. doi: 10.1007/s12008-020-00744-y

[15] Lorenzo C., Lorenzo E. Enhancing social inclusion in higher education through open access to digital fabrication laboratories, J. Inf. Tech. and Lifelong Learning 2019; 2(2): 82-87. doi: 10.20533/jitll.2633.7681.2019.0013

[16] Al-Khulaidi R.A., Akmeliawati R. et al. Development of robotic hands of signbot, advanced Malaysian sign-language performing robot. Adv. Robotics Res. 2018; 2(3) 183-199. doi: 
https://doi.org/10.12989/arr.2018.2.3.183

[17] Kausalya K., Dutta P., Sheela S. An IoT based communication system for deaf and dumb people. Eur. J. Molecular \& Clinical Medicine 2020; 7(4): 2687-2694. ISSN 2515-8260 .

[18] Proust D. 2013 in Astronomy in Sign Language at http://www.youtube.com/watch? v=ksFhan9IKKU (Retrieved Oct 2022).

[19] De Leo-Winkler M.A., Wilson G., Green W. et al. The Vibrating Universe: Astronomy for the Deaf. J. Sci. Edu. and Tech. 2019; 28: 222-230.

[20] Arcand K., Jubett A., Watzke M. et al. Touching the stars: improving NASA 3D printed data sets with blind and visually impaired audiences. J. Sci. Commun. 18(04) (2019) A01 1-22

[21] Scuba Blind International 2021: http://www.albatrosscubablindinternational.it (Retrieved Oct 2022).

[22] Lindsay S., Fuentes K. It Is Time to Address Ableism in Academia: A Systematic Review of the Experiences and Impact of Ableism among Faculty and Staff. Disabilities 2022; 2: 178-203. doi: 10.3390/disabilities2020014

[23] Bonaccio S., Connelly C.E. et al. The Participation of People with Disabilities in the Workplace Across the Employment Cycle: Employer Concerns and Research Evidence. J. Business and Psychology 2020; 35: 135-158. doi: 10.1007/s10869018-9602-5

[24] Yousaf R., Schmiede R. Barriers to women's representation in academic excellence and positions of power. Asian $\mathrm{J}$. German and European Studies 2017; 2: 2. doi 10.1186/s40856-017-0013-6
[24] Retief M.and Letšosa R. Models of disability: A brief overview. HTS Teologiese Studies/Theological Studies 2018; 74 : a4738. doi: 10.4102/hts.v74i1.4738

[26] Berghs M., Atkin K. et al. Implications for public health research of models and theories of disability: a scoping study and evidence synthesis. Public Health Res 4 2016; issue 8. doi: 10.3310/phr04080

[27] Hwang J., and Taylor J.C. Stemming on STEM: A STEM Education Framework for Students with Disabilities, J. Science Education for Students with Disabilities 2016; 19(1): 39-49. doi: 10.14448/jsesd.06.00017

[28] Griffiths A.J., J. Brady et al. STEM for Everyone: A Mixed Methods Approach to the Conception and Implementation of an Evaluation Process for STEM Education Programs for Students With Disabilities. Front. Educ. 2021; 5: 545701. doi 10.3389/feduc.2020.545701

[29] Fornauf B.S, Erickson J.D. Toward an Inclusive Pedagogy Through Universal Design for Learning in Higher Education: A Review of the Literature. J. Postsecondary Edu. and Disability 2020; 33(2): 183-199. ISSN-2379-7762

[30] Workshops 2014, 2017 on Science Dissemination for Scholars with Disabilities, ICTP-Trieste, 2014 (smr2571): http://indico.ictp.it/event/a13187, and October 2017 (smr3156): http://indico.ictp.it/event/7999 (Retrieved Oct 2022).

[31] Stark, G. 2019: Students with disabilities and scientists at work. Deaf scientist that works to ensure physics research is accessible to all. https://www.symmetrymagazine.org/article/ a-matter-of-interpretation-asl-physics (Retrieved Oct 2022). 
[32] Lee, S-M. 2022: Students with disabilities and scientists at work. He was at the pinnacle of his scientific career when an accident left him quadriplegic. His present position has given him the power to induce major changes:

https://royalsociety.org/topics-policy/diversit $y$-in-science/scientists-with-disabilities/ sang-mook-lee/ (Last visited Oct 2022).

[33] VIP 2020 @Uni - Visually Impaired People at Universities. Students with disabilities and scientists at work: https://www.vipatuni.com (Retrieved Oct 2022).

[34] Assistive technologies for people with disabilities (2018). In-Depth Analysis of European Parliament . https://www.europarl.europa.eu/stoa/en/doc ument/EPRS_IDA(2018)603218 (Retrieved June 2022).

[35] Rix J.,Garcia Carrizosa H., Hayhoe S. et al. "Emergent Analysis and Dissemination within Participatory Research", Inter. J. Res. \& Method in Edu. 2021; 44: 287-302. doi: 10.1080/1743727X.2020.1763945

[36] Soomro S A., Casakin H. and Georgiev G.V., A systematic review on FabLab environments and creativity: Implications for design. Buildings 12 (2022) 804.

[37] Petz A., Hoogerwerf E.-J. and Katerina2 M., ICCHP-AAATE 2022 Open access compendium "assistive technology, accessibility and (e)inclusion". https://epub.jku.at/obvulioa/id/7944369 (Retrieved Oct 2022).

[38] Gershenfeld N.A. "Fab: the coming revolution on your desktop -from personal computers to personal fabrication". 2005; NY: Basic Books. ISBN 10: 0465027466 